\title{
Serology in COVID: Light the Lantern and Pave the Way to Unexplored...
}

\author{
Satish Ramanathan ${ }^{1}$ (D)
}

Received: 14 October 2020/ Accepted: 20 November 2020/Published online: 2 January 2021

(C) Association of Clinical Biochemists of India 2021

\begin{abstract}
International Guidelines have voted for PCR as the Gold Standard in COVID diagnosis. Nasoparyngeal swab is the preferred specimen for PCR. It has a high probability of diagnosing early infection. But the diagnostic sensitivity of nasopharyngeal PCR decreases with increase in lapse between the infection and presentation to hospital. This might lead to dire consequences of labelling these patients as false negative, though such patients have been proved to be potentially infective since viral shedding occurs through other body fluids (stools) for long. COVID infection reveals that the IgM antibodies start to appear as early as 5th day of infection and switches over to $\operatorname{IgA}$ within 2-3 days. The aim of the study was to see if COVID antibody testing be coupled with PCR for diagnosis especially in patients presenting late (more than 14 days) of onset of infection? And if the antibodies are giving values, hence can them be reported quantitatively rather than in qualitative fashion? The second objective was to see if the COVID antibody levels be used to monitor the disease severity? And if the antibody levels of SARS CoV 2 be used an indicator to monitor the recovery?
\end{abstract}

Keywords COVID - SARS CoV 2 - Antibody levels · rtPCR

If anyone asks which is the Gold standard for COVID testing, the answer would be rt PCR (real time Polymerase chain reaction). This is the norm of the current era as dictated by the CDC (Centre for Disease Control) in form

Satish Ramanathan

satishraksha1980@gmail.com

1 MIOT Hospitals, 4/112, Mount Poonamallee Road, Manapakkam, Chennai 600089, India of interim guidelines.A very few in the medical fraternity dares to question the claims of CDC.

Is rt-PCR a Gold Standard under all circumstances? This may raise eye brows of millions of people round the globe including public health govt officials, civilians and government agencies. This article is not intended to question the validity and authenticity of PCR as the "Test Ultimatum" for diagnosis of COVID. But there are a lots of questions which have not only been itching my brains but has been doing so to many experts including Lippi and the members of IFCC and their efforts culminating in recent release of interim guidelines in IFCC very recently in month of October 6th 2020 [1] on Serological testing of antibodies against SARS-CoV-2.

The questions which had been throbbing my mind for quite some time since the release of COVID antibody assay in various platforms (especially the total antibodies whith isotypes) had been addressed the same way by IFCC committee in their recent guidelines which my mindset had been exactly upto. Though a good news per se, I had to take the news with a pinch of salt since I had thought over and was in the way of publishing the data on the same by month of early October 2020!!!

Both the national and international guidelines on COVID published so far is interim or draft but not a finalised one. This gives a hint to hidden agenda of the working committess on these areas that that is just the beginning and things may turn out in this course once more scientific evidence is obtained and new technologies continue to emerge.

This is very true with respect to serological testing in COVID infection.

CDC released a statement in month of August 2020 [2] that serology in COVID has a proven utility only as a marker for sero prevalence based on scientific evidence. 
The national ICMR guideline (Indian national guidelines) just followed the steps of CDC. Though it is understandable from the CDC and ICMR point of view, the biggest question with respect to serology in COVID is the COVID antibody testing is mere a epidemiological tool to screen the seroprevalance which we would come to know once we get into herd immunity quite in a while.

In this context, I get reminded of the infamous history of HIV, HBsAg and HCV which too took the same path where the molecular biology took the upper hand to start with but in the current context, no one needs to defend its core scientific evidence coupled with the lab practice that serology had occupied the centre stage of these testing strategies. The best example of this would be HIV wherein HIV serology (Antigen-Antibody serological combo assay) has completely replaced the viral load and grabbed the star studded status from the HIV viral load, western blot etc.; years back.

Shifting the gears to COVID testing strategy, the current world is revolving around molecular testing since it is considered to be the Gold Standard. But even a gold standard has some limitations. As per the standard protocol devised by CDC, the ideal specimen for rt-PCR testing of COVID is nasopharyngeal/oropharyngeal swab [3]. This, when subjected to PCR provides qualitative result as positive or negative. (no FDA approved/cleared assay for now is yet to quantitatively report viral load), though experts are voting for ct (cycle threshold value) which is way beyond standardisation due lack of standardisation across different PCR platforms.("comparing apples against peaches").

Hence in the current scenario, viral load is not being recommenced to monitor the response to treatment or predict disease severity or treatment response.

Serology in COVID which is neglected as the "Step Child" is not being used for diagnosis or prognosis except for seroprevalance. The irony of this fact is that there are platforms (VITROS SARS-2 COVID Total Antibodies (IgA, IgM and IgG and SARS-2 COVID IgG antibodies [4])). These can give differentiation of antibody isotypes). According to the world wide studies, the probability of detection of virrus from nasopharyngeal specimen by rtPCR starts reducing from 15 days incrementally, though the viral fragments are excreted in stools even upto 50 to 60 , days which is indicative of persistence infectivity of these patients even upto a month or two.

In this case scenario, taking serological testing in perspective of COVID, a few platforms have designed antibody isotypes apart from $\mathrm{IgG}$ antibodies.
A careful insight into the pathophysiology of COVID infection reveals that the IgM antibodies start to appear as early as 5th day of infection and switches over to $\operatorname{IgG}$ within 2-3 days.

The pilot study conducted at MIOT Hospitals, in which we had involved around 300 patients fitting into COVID diagnostic criteria showed that among 300 patients, 260 patients had COVID rt-PCR positive while rest of them had PCR negative but SARS-2 COVID Total antibody was positive. But surprisingly these patients fit into the COVID diagnostic criteria.

So this opens up an arena to following questions:

A. Diagnostic utility of serology in COVID

1) Can antibody testing be coupled with PCR for diagnosis especially in patients presenting late (more than 14 days) of onset of infection?

2) The antibodies are giving values, hence can them be reported quantitatively rather than in qualitative fashion?

B. Prognostic utility of serology in COVID

1) Can the COVID antibody levels be used to monitor the disease severity?

2) Can the antibody levels of SARS CoV 2 be used an indicator to monitor the recovery?

This warrants a large scale study to fulfil the objectives.

Funding The author wishes to declare that there was no funding provided for the manuscript.

\section{References}

1. Bohn MK, Loh TP, Wang C-B, Mueller R, Koch D, Sethi S, et al. International Federation of Clinical Chemistry (IFCC), Milan, Italy IFCC interim guidelines on serological testing of antibodies against SARS-CoV-2. Clin Chem Lab Med. 2020;58:1-8.

2. Interim guidelines for COVID antibody testing-CDC-August 2020.

3. Interim guidelines for collecting, handling, and testing clinical specimens from persons for Coronavirus Disease 2019 (COVID19)-July 8, 2020.

4. Vitros product insert total antibodies $(\mathrm{CoV} 2 \mathrm{~T})$ and $\operatorname{IgG}(\mathrm{CoV} 2 \mathrm{G})$.

Publisher's Note Springer Nature remains neutral with regard to jurisdictional claims in published maps and institutional affiliations. 